\title{
Cultural Adaptation and Piloting of iSupport Dementia in Greece
}

\author{
Areti EFTHYMIOU ${ }^{\mathrm{a}, \mathrm{b}, 1}$, Nomiki KARPATHIOU ${ }^{\mathrm{b}}$, Eleni DIMAKOPOULOU ${ }^{\mathrm{b}}$, \\ Panagiota $\mathrm{ZOI}^{\mathrm{b}}$, Chryssa KARAGIANNI ${ }^{\mathrm{b}}$, Michalis LAVDAS ${ }^{\mathrm{b}}$, \\ Anastasios MASTROYIANNAKIS ${ }^{\mathrm{c}}$, Eirini SIOTI ${ }^{\mathrm{c}}$, Ilias ZAMPETAKIS ${ }^{\mathrm{c}}$ and \\ Paraskevi SAKKA ${ }^{\mathrm{b}}$ \\ ${ }^{a}$ Quality-of-Life Lab, Department of Social Work, Hellenic Mediterranean University, \\ Heraklion, Crete \\ b Athens Association of Alzheimer's Disease and Related Disorders, Athens, Greece \\ ${ }^{\mathrm{c}}$ CMT Prooptiki, Athens, Greece
}

\begin{abstract}
The COVID-19 pandemic brought into the spotlight the technological needs of carers together with accessibility and availability of disease-related webbased services. Athens Alzheimer Association undertook the cultural adaptation of the platform iSupport in Greece. The process included multiple methodological steps based on Ecological Validity Model, and the platform was pilot tested to 15 carers of people with dementia. The duration of this project lasted for one year (April 2020-March 2021). Today more than 160 carers in Greece have registered on the platform. All 23 lessons are easily accessible by the isupportdementiagreece website.
\end{abstract}

Keywords. carers, dementia, eHealth, eLearning

\section{Introduction}

Carers make multiple decisions every day for themselves and the person with Dementia (PwD). The complexity of carers' needs depends on the type, stage of the disease, carers' knowledge, skills and attitudes towards caregiving and available health services and social network. Carers' reported needs according to the Nuffield Council of Bioethics were financial and social support, access to counselling, preservation of identity, establishing a partnership with the patient and health professionals and the access to confidential information for the cared-for person [1].

The COVID-19 pandemic has strongly influenced the needs of carers and the PwD. In a survey of 204 carers living in Greece during the lockdown in Spring 2020, the family burden has increased due to limited health service provision and access [2]. Web-based services improved carers' well-being, quality of life, alleviate the burden, increase social networking, and are cost-saving [3,4]. A higher level of eHealth literacy among carers is associated with higher self-efficacy in managing behavioural disorders [5]. In Greece, there is a lack of eLearning platforms for carers of people with dementia. The present study aimed to culturally adapt the World Health Organization iSUPPORT

\footnotetext{
${ }^{1}$ Corresponding Author, Areti Efthymiou, Quality-of-Life Lab, Social Work Department, Hellenic Mediterranean University, Estavromenos, 71410 Heraklion, Crete; E-mail: aefthymiou@hmu.gr.
} 
platform in the Greek language to support the carers with the provision of a tailor-made eLearning course during the period of lockdown in Greece. In this paper, we present the adaptation methodology and focus on the pilot-test of the platform.

\section{Methods}

\subsection{The iSUPPORT platform and the cultural adaptation phases}

The WHO developed an eLearning platform for carers of people with dementia in 2019 which was updated during the pandemic. The platform included five modules with 23 lessons in total: module 1-Introduction of dementia (lesson one), module 2-Being a caregiver (four lessons), module 3-Caring for me (three lessons), module 4-Providing everyday care (five lessons), module 5-Dealing with cognitive, psychological, and behavioural challenges (ten lessons). Athens Alzheimer association was granted by the WHO the access to adapt the platform in the Greek language culturally.

The methodology followed was based on the Ecological Validity Model [6], focusing on the adaptation of the content (language used, persons, context, names, concepts) and on the cultural adaptation process used by Teles et al [7] for the Portuguese adaptation.

A survey was organized to identify the training needs of carers in Greece. The modules were officially translated (May to June 2020), the research team checked the final translated deliverable and made minor changes. The contents were also evaluated by an expert panel of six experts working in dementia and a small group of four carers. The six experts worked in parallel and met in person to reach a consensus. After integrating experts' and carers comments, all changes were reported to WHO. At the same time, the application programming interface (API) was being developed, and the platform was customized by the contracted organization, using AngularJS, TypeScript and MongoDB. The IT representatives participated as part of the expert panel in all meetings (Figure 1).

The cultural adaptation lasted for 12 months (from April 2020 to March 2021).

\begin{tabular}{|ll|}
\hline 1. & Descriptive study of carers' web-based need \\
\hline 2. & Official translation of the iSupport Modules \\
\hline 3. & Translation check by the research team \\
\hline 4. & Evaluation by an expert panel \\
\hline 5. & Evaluation by a group of carers \\
\hline 6. & Fidelity check by the organisation \\
\hline 7. & Final adaptation of the contents \\
\hline 8. & API development \& platform customization \\
\hline 9. & Pilot test of the iSupport platform \\
\hline 10. & Expert meeting to discuss results and feedback by carers \\
\hline 11. & Update of the iSupport Platform \\
\hline
\end{tabular}

Figure 1. Methodological process of the cultural adaptation.

\subsection{Piloting methodology}

The piloting methodology followed a qualitative design with four phases: 1) the platform was presented by the research team to a group of 15 carers (pre-assessment 
phase) 2) the carers registered in the platform and used the platform according to their needs for one month (January 2021), 3) Two carers' online focus groups were organized after the end of one month (post-assessment phase). The online focus group meetings were recorded, and two researchers transcribed and analysed the discussions. All carers who participated in the focus groups received a questionnaire guide in the pre-assessment phase, 4) a consensus meeting among the experts was held to finalize the platform.

\subsection{Pilot-test participants}

A convenience sample of 15 carers participated in the pre-assessment phase; $94 \%$ $(\mathrm{N}=14 / 15)$ women, with a mean age of 50 years old, $60 \%(\mathrm{~N}=9 / 15)$ children caring for their parents most of them highly educated (tertiary education $67 \%, \mathrm{~N}=10 / 15$ ). They had attended services of the dementia center previously.

Two online focus groups were organized for the post-assessment. Of the 16 carers, $8(50 \%)$ agreed to participate in the discussions. The reason for drop-out for most carers was the lack of time due to the Holiday season (Christmas Period).

\subsection{Ethics}

The Scientific Board approved the study of the Athens Alzheimer Association. Carers were informed about the aims of the study and provided their written consent. Researchers supported carers during the pilot-phase by email and telephone if carers had queries with regards to the platform.

\section{Results}

\subsection{Experts and carers comments on the original translation}

During the evaluation of the contents by the expert panel and the group of carers, the core issues raised concerned: words and expressions, the clarity and the precision of the concepts and the scenarios, titles in Greek, available resources, and cultural adaptation of habits within the scenarios.

The group of carers mostly commented on the scenarios. In total, there were 60 scenarios in all 23 sections. Carers required more Greek related information on the resources, more in-depth information for the severe stages of dementia and more scenarios in some behavioural disorders.

\subsection{Focus group results}

Four core themes emerged from the discussion content analysis:

- Face to face interaction and sensory problems. Carers admitted that they did not always prefer online reading, and they preferred face-to-face interaction. They felt tired reading on the screen. They would prefer a downloadable option 
- Interactive aspects of the platform. They preferred an interactive version of the platform with videos and a forum where they would receive feedback from health professionals.

- Navigation issues. Carers suggested navigation changes to improve the userfriendliness of the platform.

- Cultural adapted content. New content was suggested to be included; a section for the communication with the paid carer, health services in Greece, legal and financial issues, how to treat severe dementia

\section{Discussion}

The iSupport Dementia for Greece was officially launched in March 2021 on the Greek Carers' Day (https://isupportdementia-greece.gr). Experts, carers and IT developers participated from the beginning of the adaptation process. Most of the proposed modifications have been considered providing a user-friendly platform easily accessible by a basic internet user. Before the pandemic one in two carers used eLearning services even if there was a lack of dementia-specific courses [8]. During the pandemic, iSupport eLearning course is considered a valuable tool for carers and healthcare professionals. Future research could assess the impact of the iSupport platform on caregiving variables, digital and eHealth literacy skills.

\section{References}

[1] Nuffield Council of Bioethics. The needs of carers. In: Dementia: ethical issues. 2009. p. 113-25.

[2] Tsapanou A, Papatriantafyllou JD, Yiannopoulou K, Sali D, Kalligerou F, Ntanasi E, et al. The impact of COVID-19 pandemic on people with mild cognitive impairment/dementia and on their caregivers. International Journal of Geriatric Psychiatry. 2021 Apr 1;36(4):583-7.

[3] . Dam AEH, de Vugt ME, Klinkenberg IPM, Verhey FRJ, van Boxtel MPJ. Review article: A systematic review of social support interventions for caregivers of people with dementia: Are they doing what they promise? [Internet]. Vols. 85 OP-I. 2016. p. 117.

[4] Hopwood J, Walker N, McDonagh L, Rait G, Walters K, Iliffe S, et al. Internet-based interventions aimed at supporting family caregivers of people with dementia: Systematic review. Journal of Medical Internet Research. 2018;20(6).

[5] Efthymiou A, Middleton N, Charalambous A, Papastavrou E. Health literacy and eHealth literacy and their association with other caring concepts among carers of people with dementia: A descriptive correlational study. Health and Social Care in the Community. 2021;00:1-11.

[6] Bernal G, Bonilla J, Bellido C. Ecological validity and cultural sensitivity for outcome research: Issues for the cultural adaptation and development of psychosocial treatments with Hispanics. Journal of Abnormal Child Psychology. 1995;23(1):67-82.

[7] Teles S, Napolskij MS, Paúl C, Ferreira A, Seeher K. Training and support for caregivers of people with dementia: The process of culturally adapting the World Health Organization iSupport programme to Portugal. Dementia. 2021 Feb 1;20(2):672-97.

[8] Efthymiou A, Papastavrou E, Middleton N, Markatou A, Sakka P. How caregivers of people with dementia search for dementia-specific information on the internet: Survey study. JMIR Aging 2020;3(1):e15480 